\title{
SUGGESTION OF AN ALTERNATIVE INDEX FOR PRODUCTION PERFORMANCE EVALUATION
}

\section{ELIS BERNARD KAMWA ${ }^{1}$; NELSON CARNEIRO BAIÃO ${ }^{2}$}

${ }^{1}$ Veterinary Doctor, MSc, Doctorate student, Universidade Federal de Minas Gerais, Belo Horizonte. ${ }^{2}$ Veterinary Doctor, MSc, Professor, Department of Animal Science, Universidade Federal de Minas Gerais, Belo Horizonte.

The present trial intends to suggest a new

performance index, expressed as ratio of weight gain to feed consumption, mathematically represented by the formula weight gain (kg)/feed ingestion (kg) and called Feed Yield (FY). This variable expresses the quantity of live weight produced with $1 \mathrm{~kg}$ of feed. Its value is always lesser than a unit, or $100 \%$ when expressed as percentage of feed consumption, except in too young animals in which water ingestion and retention are always very high and consequently produce enough raise in the yield. It is the case of broiler chicks, in which the cumulative Feed Yield in the first week of age is generally higher than 1, though the energy and nutrient levels of the ration are also factors that affect this index. The simplicity of its formula, the direct proportionality to performance level, the possibility to express as percentage and the applicability in various species are some of this index's advantages. This direct proportionality is particularly important because it makes the result understanding and interpretation much easier. The practical application was illustrated with data adapted from the management guide of Shaver starbro broilers (1996).

Key words: alternative index, production performance, feed yield 